$1-1-2021$

Aesthetic rehabilitation in a patient with skeletal mandibular deficiency and open bite: Journey from splinted metalloceramic prosthesis to all-ceramic crowns

Rizwan Nazeer

Shizrah Jamal

Farhan Raza Khan

Follow this and additional works at: https://ecommons.aku.edu/ pakistan_fhs_mc_surg_dent_oral_maxillofac

Part of the Dentistry Commons, and the Surgery Commons 


\section{Aesthetic rehabilitation in a patient with skeletal mandibular deficiency and open bite: journey from splinted metalloceramic prosthesis to all-ceramic crowns}

Rizwan Nazeer1, Shizrah Jamal2, Farhan Raza Khan³

\begin{abstract}
This case report is of a 31-year-old female who presented with splinted and faulty metalloceramic prosthesis on maxillary anterior teeth, which was responsible for localised periodontal disease and poor aesthetics. At multiple sites the ceramic had chipped off and the prosthesis colour did not match with the adjacent healthy teeth. A multidisciplinary approach of endodontics, periodontics and prosthodontics was employed for this case. The treatment plan consisted of removing the faulty prosthesis, endodontic retreatment of inadequately root-treated teeth and endodontics in the other coronally prepared abutment teeth. Crown lengthening surgery was performed for the correction of periodontal pockets and high smile line and maintenance of an adequate biological width. After periodontal healing, all-ceramic individual crowns were placed on the maxillary anterior teeth along with a threeunit all-ceramic bridge for the replacement of the left upper maxillary first premolar. The final results were aesthetically pleasing with good marginal fit. The patient was extremely satisfied with the outcome as all her concerns were addressed. It is, therefore, advisable to consider placing individual crowns rather than multiunit splinted prosthesis whenever possible.
\end{abstract}

Keywords: Crown lengthening surgery; all ceramic crown; periodontal disease; high smile line

\section{DOI: https://doi.org/10.47391/JPMA.860}

\section{Introduction}

Periodontitis is an inflammation of the tooth-supporting structures initiated as host response against oral bacteria and dental plaque, resulting in soft tissue damage and crestal bone loss. ${ }^{1}$ Timely diagnosis and control of active periodontal disease is very important. Failure to do so, leads to tooth mobility and eventual loss of the affected tooth. The aetiology of periodontitis is multifactorial. The corelation between restoration of tooth and adjacent

1 Department of Operative Dentistry, Bahria University Medical and Dental College, Karachi, Pakistan; 2,3Department of Surgery, Aga khan University Hospital, Karachi, Pakistan.

Correspondence: Farhan Raza Khan e-mail: farhan.raza@aku.edu periodontium is undeniable. ${ }^{2}$ Faulty margins or inappropriate contours of any dental restoration may cause excessive plaque accumulation and pose difficulty in maintaining oral hygiene. It eventually provokes an inflammatory response in the surrounding tissues leading to the development of localised periodontitis. ${ }^{3}$ Therefore, periodontal health status of any tooth is the main prognostic factor that determines the long-term survival of any restoration. 4

All crown margins should be supra-gingival or at gingival level to avoid unwanted gingival tissue response, however in cases with aesthetic concerns, it is desirable to place subgingival margins. The sub-gingival margins should always be planned with caution to avoid biological width impingement. ${ }^{3}$ Biological width of any tooth is the distance from the base of the gingival sulcus to the crestal alveolar bone. This is approximately $2 \mathrm{~mm}$, which comprises junctional epithelium and sub-epithelial connective tissue. 5 If any restoration impinges on or traumatises the biological width, severe inflammatory reaction occurs, resulting in periodontal pocket formation, apical migration of junctional epithelium and loss of clinical attachment. ${ }^{6}$ The reconstitution of the biologic width can be done successfully with crown-lengthening procedure which is indicated in cases with deep periodontal pockets when adequate amount of keratinised tissues are present. ${ }^{3}$

Porcelain fused to metal (PFM) crown is a full coverage indirect restoration that is widely used all over the world.7 Due to its high strength, reasonable aesthetics, biocompatibility and cost effectiveness, $, 8,9$ it serves as a durable and versatile dental restoration.

The central core in a PFM crown consists of coping of nickel-cobalt-chromium alloy, overlaid by several layers of dental porcelain. This results in optimum colour match of the crown with the adjacent teeth. However, various complications arise in PFM crowns over the period of time; the most common being porcelain getting chipped off and dull appearance due to presence of metal frame work, giving an artificial appearance. ${ }^{10}$

The present case report is of a 31-year-old female who underwent faulty multiunit splinted metallo-ceramic 
restoration, resulting in poor aesthetics and establishment of periodontal disease due to prosthesis by some dentist in another health facility. Although orthognathic surgery was the ideal plan but patient did not want to opt surgery. Thus, With the help of multidisciplinary approach, we improvised the facial aesthetics in a patient with gummy smile bearing short clinical crowns, deficient mandible and pocket of localised bone loss. Our management technique did not solve her dental problems but dramatically improved her dental aesthetics to a pleasing smile.

\section{Case presentation}

A 31-year-old woman presented to the dental clinics in June,2018 at the Aga Khan University Hospital for replacement of upper front dental prosthesis. The prosthesis was placed approximately 12 years back for the correction of her proclined upper front teeth. The gingiva adjoining the prosthesis used to bleed on/off and was associated with bad breath. The ceramic coating of the crowns had chipped off since then and had become unpleasant in appearance. She was otherwise healthy with no known co-morbidities and allergies. Dental history revealed that she had had multiple root canal treatments and multiple crowns.

Extra-oral examination revealed absence of any TMJ tenderness, deviation or crepitus. However, she had mildly incompetent lips and high smile line with irregular crown margins. The profile was retrognathic, buccal corridors were wide and an occlusal cant was present on the left side. Intra-oral examination revealed satisfactory oral hygiene. A splinted metal-ceramic prosthesis extended from right upper canine to left upper canine (tooth \#13-23) and there were splinted crowns on left upper first and second premolar (tooth \# 24, 25). All crowns were bulky with overhangs. Marginal gingiva around the prosthesis were smooth, shiny and inflamed with periodontal pocketing of approximately $3 \mathrm{~mm}$ along with bleeding on probing. The crown margins were irregular, over contoured and exhibited poor adaptation. Porcelain was chipped off at the gingival surfaces of the crowns, resulting in exposure of the underlying alloy. Crowns were bulky with poor anatomy and their colour did not match with the natural teeth. An open bite of approximately $0.5 \mathrm{~mm}$ was found on the closure of posterior teeth. Pre-operative extra oral and intra oral pictures were taken. The panoramic radiograph showed splinted prosthesis and inadequate root canal fillings. Post-treatment periapical disease was present in all endodontically treated teeth with evidence of apical root resorption in left upper lateral incisor. Diagnostic models were obtained for the case study. Pre-treatment records are shown in Figure 1. The problems included splinted multiunit metalloceramic prosthesis with irregular margins,

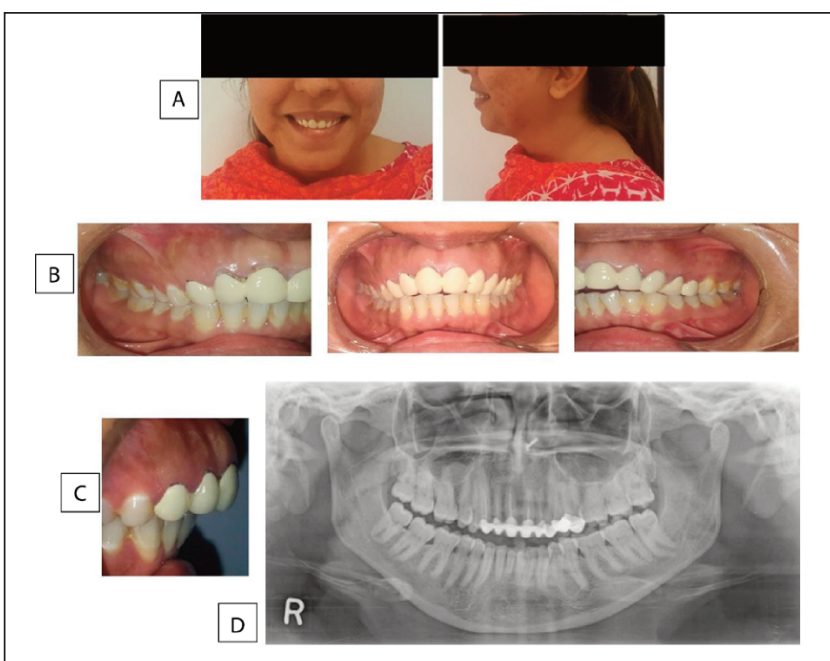

Figure-1: Pre-operative records of patient with faulty prosthesis. A: Facial frontal and lateral profile, B: Occlusion frontal and lateral profiles, C: Incisal overjet and overbite, D: Preoperative panoramic Radiograph.

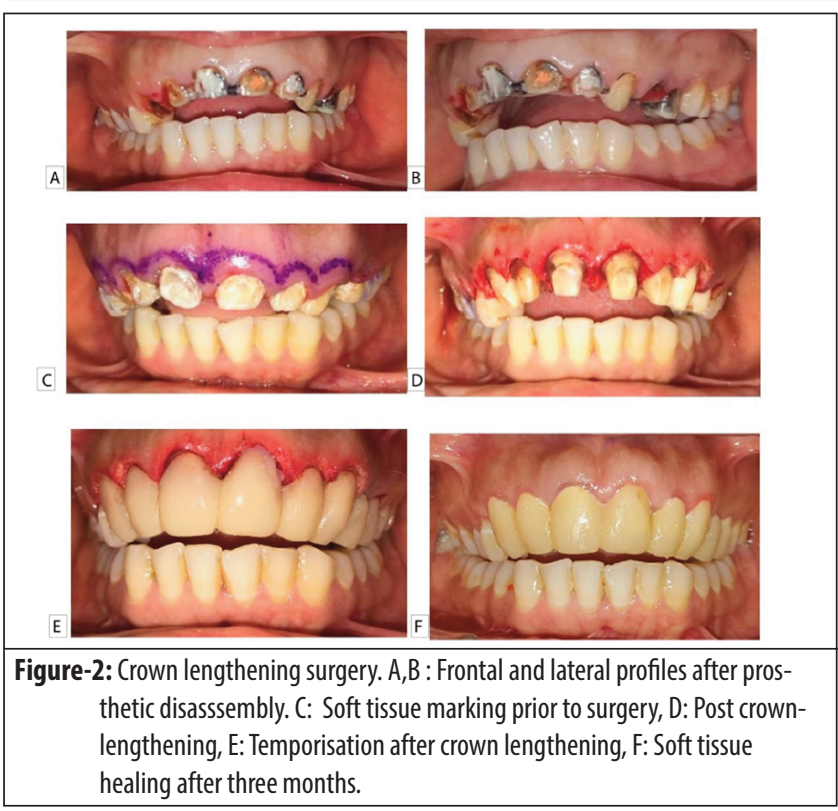

inadequate root canal filling $(13,12,11,21,22,24)$, localised chronic periodontitis with horizontal bone loss around metalloceramic prosthesis and open bite $(0.5 \mathrm{~mm})$ and excessive overjet $(6 \mathrm{~mm})$ with left maxillary occlusal cant.

Orthognathic surgery was initially advised for the correction of her baseline skeletal malocclusion. But the patient was not ready for it and wanted the most aesthetic and durable treatment plan without undergoing any major surgery. Therefore, after thorough discussion and with the patient's informed consent, assessment of all teeth for restorability was planned after disassembly of the splinted prosthesis. Redo of endodontic treatments of all strategic teeth and endodontic treatment in vital teeth was planned 


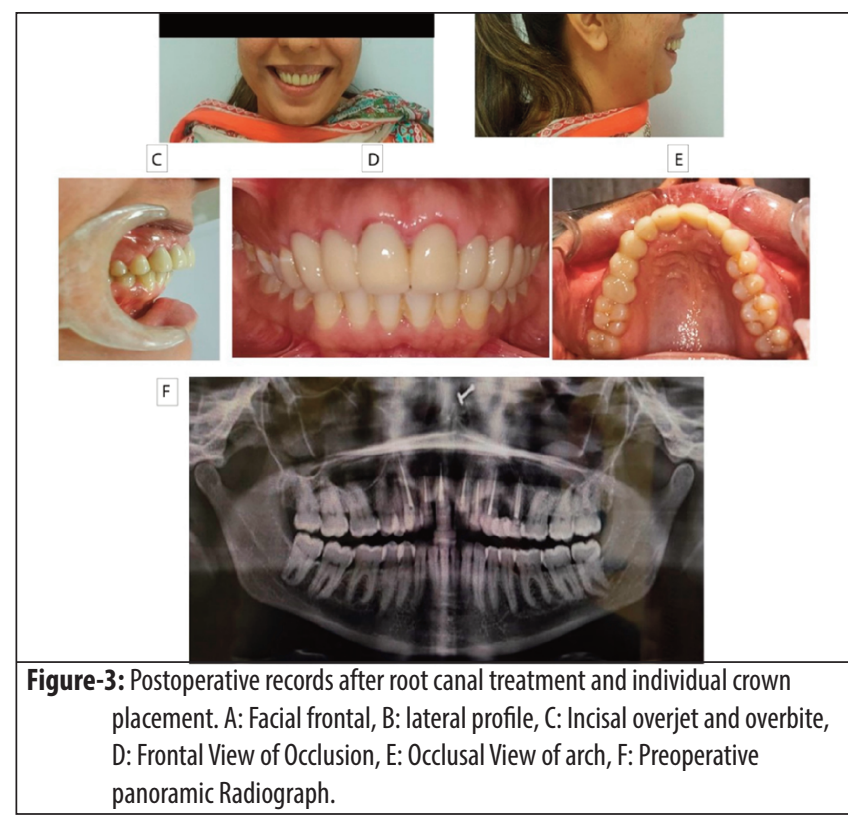

prior to crown lengthening surgery to improve pocket depths, aesthetics and gingival zenith. Provision of new crowns/bridge (all-ceramic) with improved aesthetics was the final plan proposed to her.

Initially, diagnostic casts were mounted on the semi adjustable articulator (Hanau Articulator, Teledyne Hanau Buffalo, NY, USA) ${ }^{11}$ using Hanau facebow. A vacuum formed stent (3a Medes, Easy - Vac Gasket, Korea) ${ }^{12}$ was fabricated. The left upper first premolar was a broken-down root with inadequate ferrule; therefore, it was extracted, sutures were placed and a temporary acrylic bridge (Integrity, Temporary Crown \& Bridge Material, Dentsply, USA), fabricated using vacuum-formed stent, was then luted with temporary cement (GC, Freegenol temporary pack, GC America).13 Following that, endodontic retreatments of all inadequately root-treated teeth (\# 13, 12, 11, 21 and 22) and elective endodontic treatments on remaining abutment teeth $(\# 23,25)$ were done. Post-obturation $x$-rays showed all teeth root canal fillings up to the length (figure 3). In the subsequent appointment, markings were made for crown lengthening surgery (gingivectomy) using an indelible pencil and $2-3 \mathrm{~mm}$ marginal gingival tissues were excised (figure 2). Care was taken to maintain the biologic width. All the teeth were then prepared for all-ceramic crowns and a new temporary acrylic bridge was fabricated.

Gingival tissues were allowed to heal for six weeks. Postoperative instructions were thoroughly reinforced. After three months, gingival tissues showed remarkable healing with significant improvement in aesthetics (figure 3). Periodontal examination revealed the maximum probing depth of $1.5 \mathrm{~mm}$ with no bleeding on probing. Impressions were obtained (Aquasil Ultra Putty Soft Regular and Aquasil
Ultra-Light bodies, DENTSPLY, USA) ${ }^{14}$ for all ceramic crowns. Interocclusal records were taken using bimanual manipulation method. Working casts were then attached on semi-adjustable articulator using interocclusal records (Hanau Articulator, Teledyne Hanau Buffalo, NY, USA). ${ }^{11}$ The temporary bridge was placed back. Impressions were sent to the lab for fabrication of all-ceramic crowns (\# 13, 12, 11, 21, and 22) and a bridge (\#23-25) (IPS e-max Ceram, Ivoclar vivadent, Leichtenstein. Germany). ${ }^{15}$ After 10 days, bisque bake trial was done in which occlusion, shape and shade of all ceramic crowns were evaluated and showed to the patient. The patient wanted removal of ceramic from the labial surface of incisal thirds to camouflage her protruded profile; therefore, adjustments were made accordingly. Allceramic crowns were then glazed and bonded (RelyX Unicem, U100: Self-Adhesive Universal Resin Cement, 3M ESPE). ${ }^{16}$ The final occlusal scheme was mutually protective (Lateral guidance on canines and anterior guidance was evenly given by all anterior teeth. The overjet was $2 \mathrm{~mm}$ and overbite was $1 \mathrm{~mm}$. Ideal incisors relationships could be achieved with orthognathic surgery; however, the patient was extremely happy with the outcome of the treatment. The anatomical shape and shade match of all ceramic crowns was also appropriate. Oro-facial aesthetics were significantly improved. Post-treatment records are shown in figure 3. All endodontic and re-endodontic treatments were adequate and crowns were well-seated on the margins. The patient was extremely satisfied with the outcome as all concerns were well addressed.

\section{Discussion}

Inadequate canal obturation is an important factor which determines the success of any endodontic treatment. It may result in certain complications such as post-treatment apical periodontitis, apical root resorption, etc. 17,18 It is important to assess the quality of root canal obturation before planning any indirect restoration for endodontically treated teeth. ${ }^{17}$ It not only provides long-term success of a restoration, but also avoids financial burden on the patient. In our patient all endodontically treated teeth (\# 13, 12, 11, 21 , and 22) were inadequately root filled and one tooth (\#12) had apical root resorption. Therefore, we planned endodontic retreatments in these teeth and elective root canal treatments in remaining teeth (\#13 and 15) before placing all-ceramic restorations. All root canals were thoroughly debrided and obturated up to the correct length.

Open bite and mandibular deficiency in females can result in excessive gingival display. Prosthodontic treatment in these cases pose a big clinical challenge. High smile line is often a concern with high aesthetic demands. It can be corrected by various methods which include crown 
lengthening surgery, orthodontics, orthognathic surgery, injecting botulism toxins or myotomies. ${ }^{19}$ The most common method employed or extensively reported in the literature for its management is crown lengthening surgery (gingival recontouring with or without osseous surgery).19 It establishes the desired gingival margin position while simultaneously avoiding violation of the biologic width. ${ }^{20}$ A waiting period of approximately 4-6 weeks is usually required for optimal healing of gingival tissues before obtaining impression for indirect full coverage restoration.20,21 In our patient, aesthetics was a main concern due to high smile line, therefore we performed gingival recontouring of all the teeth. Biological width was preserved and adequate time span was allowed for optimum healing of gingival tissues. Ideal gingival aesthetics were achieved and high smile line was replaced with average smile line.

Dental malpractice/quackery does more harm to the patient than any benefit, especially if it's related to irreversible interventions such as root canal and fixed prosthodontic treatment. Splinted prosthesis is usually recommended in cases of dental implants which are surrounded by poor quality bone. It is usually done to reduce the stress by disseminating it horizontally. 22 Placing fused/splinted metalloceramic fixed prosthesis (single casting) in a situation where all natural abutments are present is a periodontal catastrophe. The individual unit crowns are the standard of care in this situation as it ensures integrity of periodontal tissues and offers ease in oral hygiene maintenance. 23 In our patient multiunit porcelain fused to metal restorations were designed resulting in localised periodontal disease (inflamed, erythematous periodontal tissue with pocketing). Therefore, we replaced multiunit splinted PFM crowns with individual crowns which facilitate interdental cleaning with dental floss and facilitated periodontal healing.

With advancement in various ceramic types, all-ceramic indirect full coverage restoration are the preferable indirect full coverage restorations because of excellent aesthetics and durability. ${ }^{24}$ Lithium disilicate (particularly IPS E.max) crowns are now becoming popular in dentistry due to their strength and realistic appearance.24,25 Therefore, keeping in mind all the expectations of the patient, we placed allceramic E.max crowns. The patient was satisfied with the treatment outcome.

Whenever natural teeth are prepared for full coverage restorations, consideration should be given to individual crown placement. It should be done to avoid unhygienic circumstances eventually leading to periodontal destruction. A prudent clinician should carry out treatment planning by focusing on the patient's concerns. This include selecting treatment modalities which have predictability, and longevity and are supported with scientific evidence. Aesthetics should be an integral part of treatment planning. An improved appearance brings self-esteem and boosts the self-confidence of the patients. In this case, maxillary prognathism would have been managed ideally with orthodontic surgery, however, the patient rejected the surgical option and the protruded profile was camouflaged with multidisciplinary approach of endodontics, periodontics and prosthodontics.

\section{Conclusion}

The current case report elucidates step by step management of a patient presented with faulty multiunit splinted metallo-ceramic restoration with advance periodontal tissues destruction. Initially crown lengthening surgery was performed along with placement of temporary bridge for six weeks, allowed healing of periodontal tissues and correction of gingival aesthetics. It was followed placement of individual all ceramic full coverage by restorations for correction of dento-facial aesthetics and to ensure integrity of periodontal tissues and offers ease in maintenance of oral hygiene.

\section{Disclaimer: None.}

Conflict of Interest: One of the co-author is Section head, Service line Chief.

\section{Funding Sources: None.}

\section{References}

1. Silva N, Abusleme L, Bravo D, Dutzan N, Garcia-Sesnich J, Vernal R, et al. Host response mechanisms in periodontal diseases. J Appl Oral Sci. 2015; 23:329-55.

2. Beukers NG, van der Heijden GJ, van Wijk AJ, Loos BG. Periodontitis is an independent risk indicator for atherosclerotic cardiovascular diseases among 60174 participants in a large dental school in the Netherlands. J Epidemiol Community Health. 2017; 71:37-42.

3. Nugala B, Kumar BS, Sahitya S, Krishna PM. Biologic width and its importance in periodontal and restorative dentistry. J Conserv Dent. 2012; 15:12-7.

4. Felippe LA, Monteiro Junior S, Vieira LC, Araujo E. Reestablishing biologic width with forced eruption. Quintessence Int. 2003; 34:7338.

5. Jorgić-Srdjak K, Plančak D, Maričević T, Dragoo MR, Bošnjak A. Periodontal and prosthetic aspect of biological width part I: Violation of biologic width. Acta stomatologica Croatica. 2000; 34:195-7.

6. Singh K, Gupta N, Chowdhary N. Effects Of Tooth Preparation And Poorly Designed Artificial Crowns On Health Of Periodontium And Esthetics: A Case Report. J Pharm Biomed Sci.2012; 24: 12-5.

7. Ozcan $M$, Niedermeier W. Clinical study on the reasons for and location of failures of metal-ceramic restorations and survival of repairs. Int J Prosthodont. 2002; 15:299-302.

8. Anusavice KJ, Kakar K, Ferree N. Which mechanical and physical testing methods are relevant for predicting the clinical performance of ceramic-based dental prostheses? Clin Oral Implants Res. 2007; 18:218-31.

9. Levi L, Barak S, Katz J. Allergic reactions associated with metal alloys in porcelain-fused-to-metal fixed prosthodontic devices-A system- 
atic review. Quintessence Int.2012; 43:871-7.

10. Al-Moaleem MM, Aldhalai MA, Al-Sanabani FA, Assiri KA, Tarrosh MY. Replacement of multiunit joined porcelain fused to metal restoration with an esthetic separated all ceramic crowns: Clinical and technical report. Saudi J Med Med Sci. 2015; 3:71.

11. Mix W. Hanau ${ }^{\text {TM } W i d e-V u e ~[O n l i n e] ~[C i t e d ~} 2019$ September 11]. Available from: URL: https://whipmix.com/products/hanau-wide-vue/.

12. 3A Medes. Gaskets [Online] [Cited 2018 March 22]. Available from: URL: http://www.3amedes.co.kr/eindex2_5.php.

13. Pattersondental.com. Freegenol ${ }^{T M}$ Temporary Cement, 1-1 Pack - GC America Inc. [Online] [Cited 2019 Jun 12].Available from: https://www.pattersondental.com/Supplies/ProductFamilyDetails/PI F_67945. Page not found

14. Dentsply Sirona. Aquasil Soft Putty Regular Set, 2x450ml (60578320). [Online] [Cited 2019 Jun 12].Available from:URL: https://www.dentsplyestore.com.au/aquasil-soft-putty-regular-set2x450ml-60578320/w1/i1004580/.

15. IPS e.max Ceram. [Online] [Cited 2019 Jun 12].Available from: Available from: URL: https://www.ivoclarvivadent.com/en/p/all/ips-emaxceram/

16. 3m.com. Rely $X^{\mathrm{TM}}$ Unicem Self-Adhesive Universal Resin Cement $\mid 3 \mathrm{M}$ United States. [online][cited 2019 Jul 14]. Available from: URL: https://www.3m.com/3M/en_US/company-us/all-3mproducts/ /relyx-unicem-RelyX-Unicem-Self-Adhesive-UniversalResin-Cement/?N=5002385+3294768486\&rt=rud

17. Tabassum S, Khan FR. Failure of endodontic treatment: The usual suspects. Eur J Dent. 2016; 10:144-7.
18. Siqueira JF Jr, Rocas IN, Ricucci D, Hulsmann M. Causes and management of post-treatment apical periodontitis. Br Dent J. 2014; 216:30512.

19. Moura D, Lima E, Lins R, Souza R, Martins A, Gurgel B. The treatment of gummy smile: integrative review of literature. Rev Clin Periodoncia Implantol Rehabil Oral. 2017; 10:26-8.

20. Narayan S, Narayan TV, Jacob PC. Correction of gummy smile: A report of two cases. J Indian Soc Periodontol. 2011; 15:421-4.

21. Oakley E, Rhyu IC, Karatzas S, Gandini-Santiago L, Nevins M, Caton J. Formation of the biologic width following crown lengthening in nonhuman primates. Int J Periodontics Restorative Dent. 1999; 19:529-41.

22. Wang TM, Leu LJ, Wang J, Lin LD. Effects of prosthesis materials and prosthesis splinting on peri-implant bone stress around implants in poor-quality bone: a numeric analysis. Int J Oral Maxillofac Implants. 2002; 17:231-7.

23. Mahboub F, Fard EM, Geramipanah F, Hajimiragha H. Prosthodontic rehabilitation of a bruxer patient with severely worn dentition: a clinical case report. J Dent Res Dent Clin Dent Prospects. 2009; 3:28-31.

24. Zawta C. Fixed partial dentures with an all-ceramic system: a case report. Quintessence Int. 2001; 32:351-8.

25. Gisler V, Enkling N, Zix J, Kim K, Kellerhoff NM, Mericske-Stern R. A multidisciplinary approach to the functional and esthetic rehabilitation of amelogenesis imperfecta and open bite deformity: a case report. J Esthet Restor Dent. 2010; 22:282-93. 